\title{
RUANG KOMUNITAS DI PESANGGRAHAN
}

\author{
Gilbert Japutra $^{1)}$, Suryono Herlambang ${ }^{2)}$ \\ 1)Program Studi S1 Arsitektur Universitas Tarumanagara, gilbert.315150089@stu.untar.ac.id \\ 2) Program Studi S1 Perencanaan Wilayah dan Kota, Fakultas Teknik, Universitas Tarumanagara, suryonoh@ft.untar.ac.id \\ Masuk: 10-01-2020, revisi: 28-01-2020, diterima untuk diterbitkan: 09-05-2020 (doi: 10.24912/stupa.v2i1.6852)
}

\begin{abstract}
Abstrak
Kota saat ini merupakan salah satu bukti bahwa manusia telah menjalani kehidupan baru yang modern dengan berbagai perkembangan teknologi yang membuatnya berkembang, aktivitias manusia masa kini semakin kompleks, mengubah gaya hidup mereka. Manusia sejak awal telah menciptakan ruang sebagai wadah aktivitas hidup mereka. Ruang-ruang ini menjadi pusat kegiatan manusia dan dari ruang ini terbentuk komunitas yang berisi manusia-manusia dengan tujuan yang sama. Ruang komunitas menjadi salah satu tempat bagi manusia untuk berkoneksi dengan manusia lain, menghilangkan kejenuhan dari kesibukan sehari-hari, ruang ini menjadi tempat ketiga bagi mereka. Pesanggrahan merupakan salah satu area yang ramai dengan hunian dan kurang adanya fasilitas pewadah interaksi komunitas, apalagi dengan cukup banyak hunian vertikal yang ada disekitarnya keberadaan sebuah ruang public yang netral sangat dibutuhkan. Proyek ini bertujuan untuk menjawab kebutuhan masyarakat pesanggrahan khususnya penghuni Puri Park View dan sekitarnya akan ruang komunitas yang netral dan nyaman. Dengan banyaknya ruang publik yang semakin di komersialkan keberadaan ruang komunitas semakin dicari-cari. Metode perancangan yang digunakan berupa pendekatan Proxemics yang didasari oleh buku Edward Hall The Silent Language dan studi Ergonomi manusia. Keduanya digunakan dengan tujuan untuk meleburkan ruang personal agar memungkinkan terbentuknya sebuah ruang komunitas yang nyaman, informal dengan kesan santai bagi penggunanya.
\end{abstract}

Kata kunci: aktivitas; arsitektur; komunitas; ruang; urban

\begin{abstract}
The City today is one of many proofs that humans now lead a new and modern life with multiple technological advancements that supports it, human activities become complex thus altering their lifestyle. Humans have been creating spaces to contain their daily activites. These spaces translates as a hub and from these hubs create communites where humans with the same goals and interests gather. Community Spaces is one of the places where humans connect and take a break from their daily activities and becomes a Third place for them. Pesanggrahan is one of many urban areas that lacks public facilities that accomodates its inhabitants. Developments of vertical housings nearby makes it even urgent to address the lack of community spaces that provide and accomodates its nearby inhabitants. With the developments of modern public spaces being further and further commercialized, this emphasizes the need to develop a special community space with its purpose to solely provide and serve communities nearby. The methods of study used to respond to this matter are Proxemics and Human Ergonomics Study. Where as these two methods are used to try and fuse personal spaces in order to try and create a community space that is Comfortable, Informal and relaxing to its users.
\end{abstract}

Keywords: activities; architecture; community; space; urban

\section{PENDAHULUAN}

Kota saat ini merupakan salah satu bukti bahwa manusia telah menjalani kehidupan baru yang modern, dengan berbagai perkembangan teknologi yang membuatnya berkembang, aktivitias manusia masa kini semakin kompleks, mengubah gaya hidup mereka. Sejak awal 
keberadaannya, manusia telah menciptakan ruang untuk mewadahi kelangsungan hidupnya baik secara individual maupun kelompok. Dengan ini, arsitektur menjadi tanda dalam sejarah bahwa manusia selalu berkembang entah ke arah yang baik atau buruk. Di tengah perkembangan yang pesat dan kegiatan yang rumit manusia selalu mencoba mencari sebuah ruang bagi mereka untuk sejenak berhenti, dan keluar dari kesibukan. Sebuah ruang yang berada di antara rumah dan pekerjaan mereka, yaitu tempat ketiga.

Setiap manusia memiliki pandangan tersendiri mengenai apa itu tempat ketiga mereka. Parameter kenyamanan tempat ketiga setiap manusia tentu berbeda-beda dan menyesuaikan dengan mood, keadaan dan keinginan saat itu. Rumah memanglah sebuah tempat dimana manusia bisa beristirahat dengan tenang, namun rumah bisa membuat orang merasa sendiri. Kantor memanglah tempat untuk kerja, namun duduk di kantor seharian belum tentu meningkatkan produktivitas seseorang. Oleh sebab itu manusia membutuhkan ruang ketiga yang bisa memenuhi kebutuhannya.

Hubungan antara makanan dan arsitektur selalu menarik untuk ditelusuri. Pergerakan makna dari kegiatan 'memakan' selalu beriringan dengan nilai dari ruang yang melingkupinya. Makanan dan kegiatan 'memakan' telah bergerak dari sekedar sebuah kebutuhan primer menjadi sesuatu yang mempunyai nilai simbolik. Dalam kegiatan makan inilah makanan dan proses memakannya menghadirkan makna pada ruang dan tempat dalam arsitektur.

\section{Identifikasi Masalah}

Dari latar belakang tersebut, terdapat identifikasi masalah yang akan dijadikan bahan penelitian antara lain sebagai berikut:

1. Jenuhnya manusia dengan rutinitas rumah dan kantor membuat mereka membutuhkan sebuah ruang ketiga yang dimana mereka bisa menyendiri maupun berinteraksi secara sosial.

2. Makan menjadi salah satu kegiatan manusia yang dapat memicu interaksi sosial, namun masyarakat masa kini lebih suka membawa makanan mereka pulang, ini menyebabkan minimnya interaksi sosial dan manusia mulai lari ke ruang virtual.

3. Perkembangan arsitektur terhadap kegiatan manusia dalam makan tidak menjawab kebutuhan manusia secara sosial yaitu memicu interaksi sosial

4. Interaksi sosial antara manusia semakin minim dan hanya sebatas untuk memenuhi kebutuhan pribadinya.

5. Pandangan manusia terhadap interaksi dengan orang tidak dikenal semakin negatif, manusia cenderung semakin individualis dan menyendiri maupun berkelompok secara eksklusif.

\section{DAILY MODERN HUMAN CYCLE}
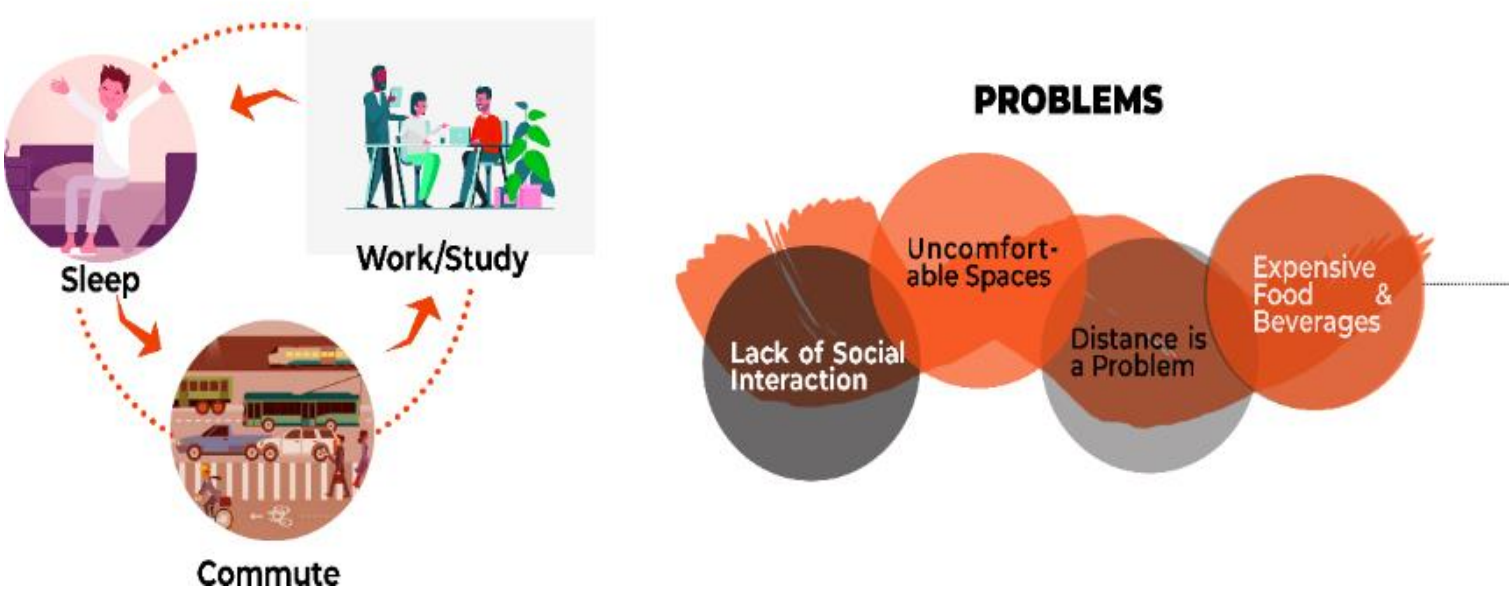

Gambar 1. Diagram Problematika Manusia Masa kini Sumber: Penulis, 2019 


\section{KAJIAN LITERATUR}

\section{The Great Good Place (Ray Oldenburg) \\ Third place}

Pada dasarnya terdapat 2 tempat yang ada kehidupan masyarakat, yaitu yang disebut first place dan second place. Menurut Ray Oldenburg, First place merupakan suatu tempat yang biasa berupa hunian bagi seorang atau banyak individu.Second place merupakan tempat dimana seorang individua tau banyak melakukan kegiatan pekerjaannya, seperti kantor tempat bekerja atau sekolah. Selain dua tempat tersebut, ada tempat lain yang menjadi penunjang masyarakat selain kedua tempat pokok tersebut, Tempat ini berupa taman atau open space yang fungsinya juga sebagai penunjang keindahan kota. Taman atau open space ini merupakan ruang yang menjadi bagian dari third place. Third place merupakan suatu tempat, area, atau ruang yang menyuguhkan program berupa rekreasi untuk penduduk sekitarnya.

Dalam bukunya Great Good Place, Ray Oldenburg menyebutkan bahwa sebuah thirdplace merupakan suatu fasilitas yang dapat menunjang kualitas hidup penduduk atau komunitas sekitarnya. Third place juga disebut sebagai 'Living Room of Society', yang berarti ruang keluarga masyarakat, dimana seorang individu/masyarakat dapat bersantai di area publik, bertemu dengan orang - orang baru dan bersosialisasi, bertukar pikiran satu dengan yang lain, hingga bangun sebuah relasi.

\section{Teori Kepribadian Myers-Briggs}

Setiap individu manusia memiliki ciri-ciri kepribadian yang berbeda satu dengan yang lainnya. Secara umum, kepribadian seseorang dapat dibagikan kedalam dua sifat, yaitu: (1) extrovert dan (2) introvert.

\section{Extrovert (E)}

Kepribadian ini suka mendapatkan energi dari keterlibatan aktif dalam acara dan memiliki banyak kegiatan yang berbeda. Mereka juga senang ketika berada di sekitar orang dan suka memberikan energi kepada orang lain. Manusia dengan kepribadian ini suka beraksi dan mewujudkan sesuatu. dan umumnya merasa betah di dunia. Extrovert sering memahami suatu masalah dengan lebih baik ketika dapat berbicara dengan lantang tentang hal itu dan mendengar apa yang orang lain katakan. Pernyataan berikut secara umum berlaku untuk Extrovert:

1. Saya dilihat sebagai "outgoing/suka berpergian" atau sebagai "senang bergaul."

2. Saya merasa nyaman dalam kelompok dan suka bekerja di dalamnya.

3. Saya punya banyak teman dan mengenal banyak orang.

4. Saya terkadang melompat terlalu cepat ke dalam suatu kegiatan dan tidak memiliki cukup waktu untuk memikirkannya.

5. Sebelum saya memulai suatu proyek, kadang-kadang saya lupa untuk berhenti dan menjelaskan apa yang ingin saya lakukan dan mengapa.

Introvert (I)

Individu dengan kepribadian ini suka mendapatkan energi dari berurusan dengan ide, gambar, ingatan, dan reaksi yang ada di dalam kepala mereka. Introvert seringkali lebih suka melakukan hal-hal sendirian atau dengan satu atau dua orang yang dirasa nyaman dengannya. Kepribadian ini cenderung mengambil waktu untuk berpikir sehingga ia memiliki ide yang jelas tentang apa yang akan ia lakukan ketika mereka memutuskan untuk bertindak. Gagasan adalah hal yang hampir solid baginya. Terkadang mereka lebih menyukai gagasan tentang sesuatu yang lebih baik daripada sesuatu yang asli.

Pernyataan berikut secara umum berlaku untuk kepribadian introvert:

a. Saya dipandang sebagai "reflektif" atau "pendiam."

b. Saya merasa nyaman sendirian dan suka hal-hal yang bisa saya lakukan sendiri. 
c. Saya lebih suka mengenal beberapa orang dengan baik.

d. Terkadang saya menghabiskan terlalu banyak waktu untuk merenung dan tidak bergerak cukup cepat.

\section{The Silent Language (Edward Hall)}

Proxemics didefinisikan sebagai studi tentang aspek budaya, perilaku, dan sosiologis dari jarak spasial antara individu. Diperkenalkan oleh antropolog Edward T. Hall pada tahun 1960an, teori ini awalnya muncul dari studi tentang perilaku hewan yang dilakukan pada abad ke-19 dan awal abad ke-20 dan kemudian berkembang mendasarkan pada pengamatan manusia dalam situasi sosial. Dalam bukunya, The Silent Language, Edward Hall menguraikan klasifikasi jarak berikut di balik teori proksemik yang telah dijelaskan dan diterjemahkan dalam konteks lingkungan restoran:

1. Public Distance (Jarak Publik) - 360cm dan seterusnya: Perasaan jarak dirasakan saat memasuki Restoran beratap tinggi atau lobi terbuka yang besar.

2. Social Distance (Jarak Sosial) $-120 \mathrm{~cm}$ sampai $360 \mathrm{~cm}$ : Pelanggan merasa jarak sosial ketika mereka menonton layar televisi di atas sebuah bar.

3. Private Distance (Jarak Pribadi) - $40 \mathrm{~cm}$ sampai $120 \mathrm{~cm}$ : Jarak pribadi biasanya terjadi antara orang yang merupakan anggota keluarga atau teman dekat. Semakin dekat orang dapat berdiri dengan nyaman sementara berinteraksi dapat menjadi indikator keintiman hubungan. Jarak ini di restoran adalah pengalaman ketika berbicara di meja untuk makan pendamping.

4. Intimate Distance (Jarak intim) - terjadinya kontak fisik hingga $45 \mathrm{~cm}$ : Pada tingkat jarak ini sering menunjukkan hubungan yang lebih dekat atau kenyamanan besar antara individu. Kami berbicara tentang jarak intim dalam konteks Restoran ketika seseorang cukup dekat untuk menyentuh pendamping makan, seperti ketika duduk berdampingan pada sebuah banket. Ini adalah perasaan yang terkadang ramai ketika kursi makan malam dipenuhi oleh staf layanan yang lewat. (R. S. Baraban, 1989)

\section{METODE}

\section{Kepribadian manusia extrovert/introvert}

Metode ini digunakan untuk menentukan jenis zona dan area yang cocok bagi setiap individu secara garis besar berdasarkan kepribadian mereka.

\section{Proksemiks}

Metode ini digunakan untuk menentukan Batasan-batasan kenyamanan setiap individu sebagai user. Dengan memahami Batasan kenyamanan antar manusia, penulis dapat menentukan jenisjenis ruang yang dapat diciptakan yang nantinya akan di sesuaikan dengan kepribadian masingmasing individu berdasarkan jarak intim dan sosial setiap orang

\section{Studi Ergonomi Manusia}

Setelah menentukan kepribadian dan jarak intim dan sosial seseorang, penulis akan melakukan studi ergonomi manusia untuk menentukan detail dan ukuran furnitur untuk tiap-tiap zona dan ruang yang akan diciptakan.

\section{DISKUSI DAN HASIL}

\section{Profil Kawasan}

Kawasan yang dipilih berada di Kelurahan Meruya Utara, tepatnya berada di Jalan Pesanggrahan Raya tepat di depan Apartemen Puri Park View. Jangkauan pelayanan program yang dirancang sekitar $1 \mathrm{~km}$ dari tapak yang terpilih. 


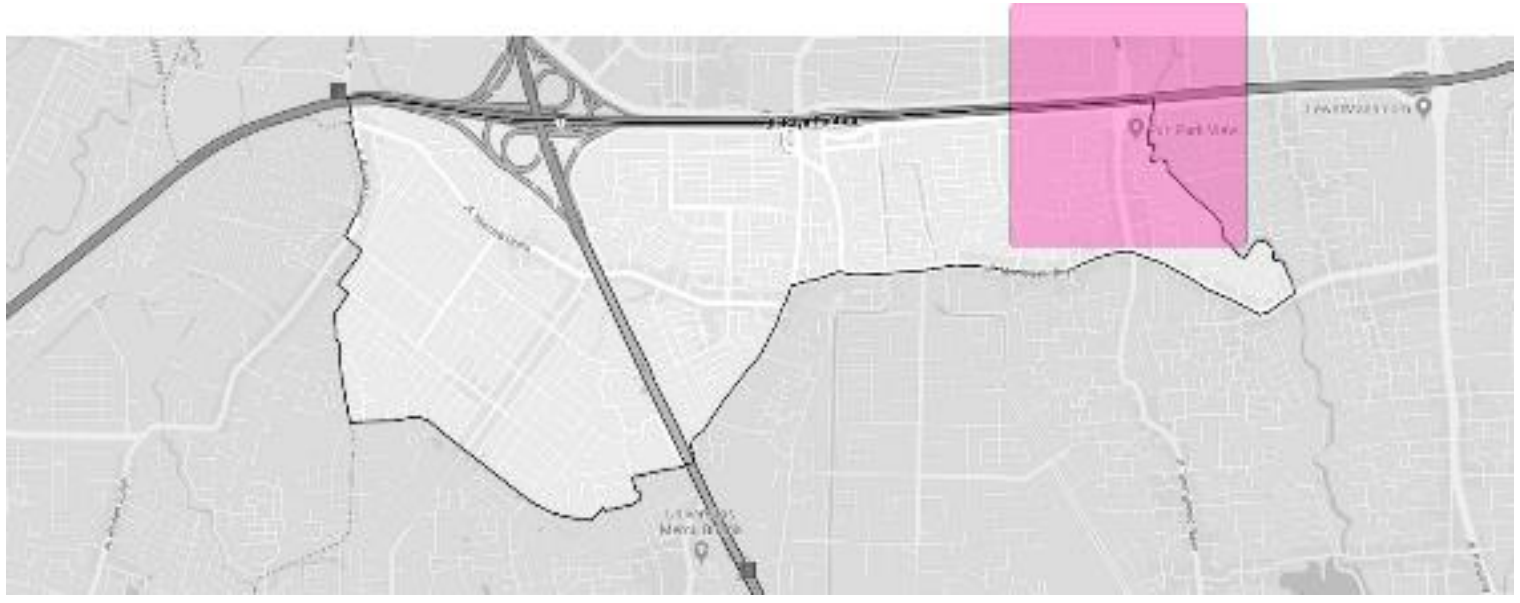

Gambar 2. Peta Kelurahan Meruya Utara

Sumber: Penulis, 2019

Profil Penduduk

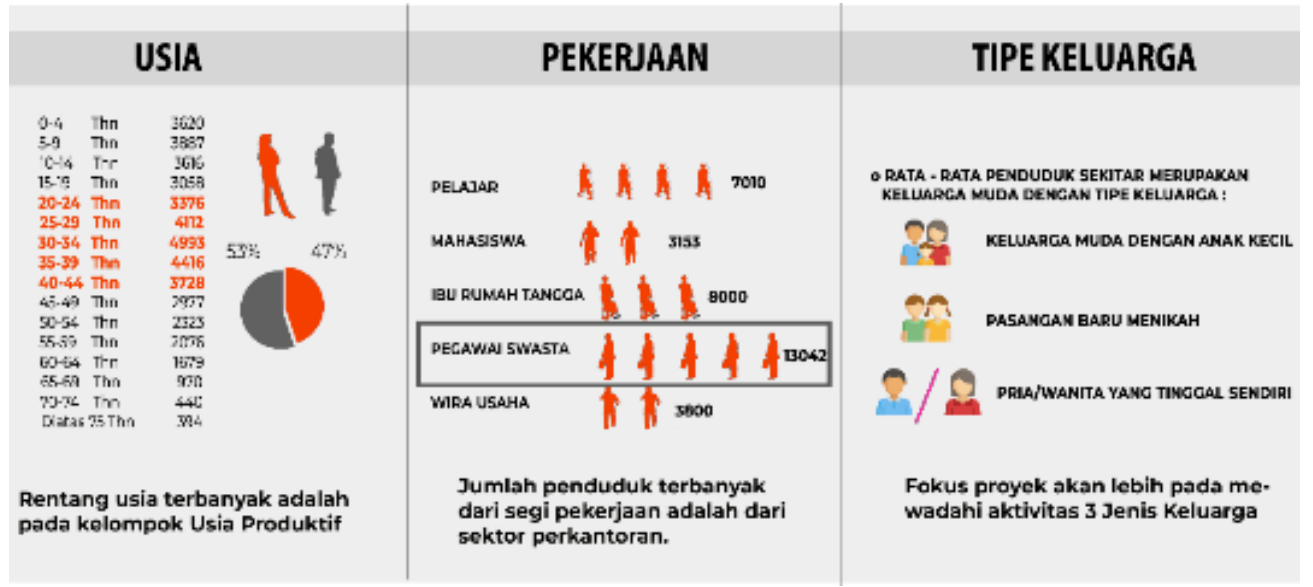

Gambar 3. Infografik Penduduk Meruya Utara

Sumber: Penulis, 2019

Target penduduk yang dilayani difokuskan pada rentang umur 20-44 tahun dengan Pekerjaan utama pegawai swasta. Program juga tidak menutup kemungkinan untuk melayani kelompok usia lain seperti anak-anak dan lansia.

\section{Usulan Program}

Usulan program yang dirancang berfokuskan pada kegiatan yang dilakukan sehari-hari oleh penduduk sekitar, sehingga program yang terpilih tidak bersifat musiman melainkan dapat melayani penggunanya dalam kegiatan sehari-hari. Program yang akan diambil berasal dari kegiatan yang sudah terjadi sebagai bagian dari karakteristik kegiatan sehari-hari dan kebutuhan interaksi antar masyarakat yang belum terpenuhi dengan baik.

\section{Food Space}

Untuk mewadahi kebutuhan akan tempat makan (bukan restoran) penduduk sekitar. Mencoba mengubah kebiasaan penduduk sekitar yang suka makan di rumah dan menyebabkan kurangnya interaksi sosial baik dari verbal dan non verbal.

\section{Wellness Community Club}

Mencoba mewadahi kebutuhan pelajar sekitar akan tempat belajar bersama yang nyaman dan gratis. Paling tidak mengajak pelajar untuk mau mengerjakan tugasbersama-sama temannya sepulang sekolah 


\section{Rooftop Garden}

Ruang Hijau publik untukmemperindah dan sebagai ruang bermain semua kalangan mulai dari anak hingga lansia. Ruang ini ditargetkan mewadahi kegiatan mulai dari taman bermain hingga area senam.

\section{Area Komersil}

Lantai 1 bangunan dirancang sebagai Area Komersil sehingga program bangunan

\section{Analisis Lokasi}

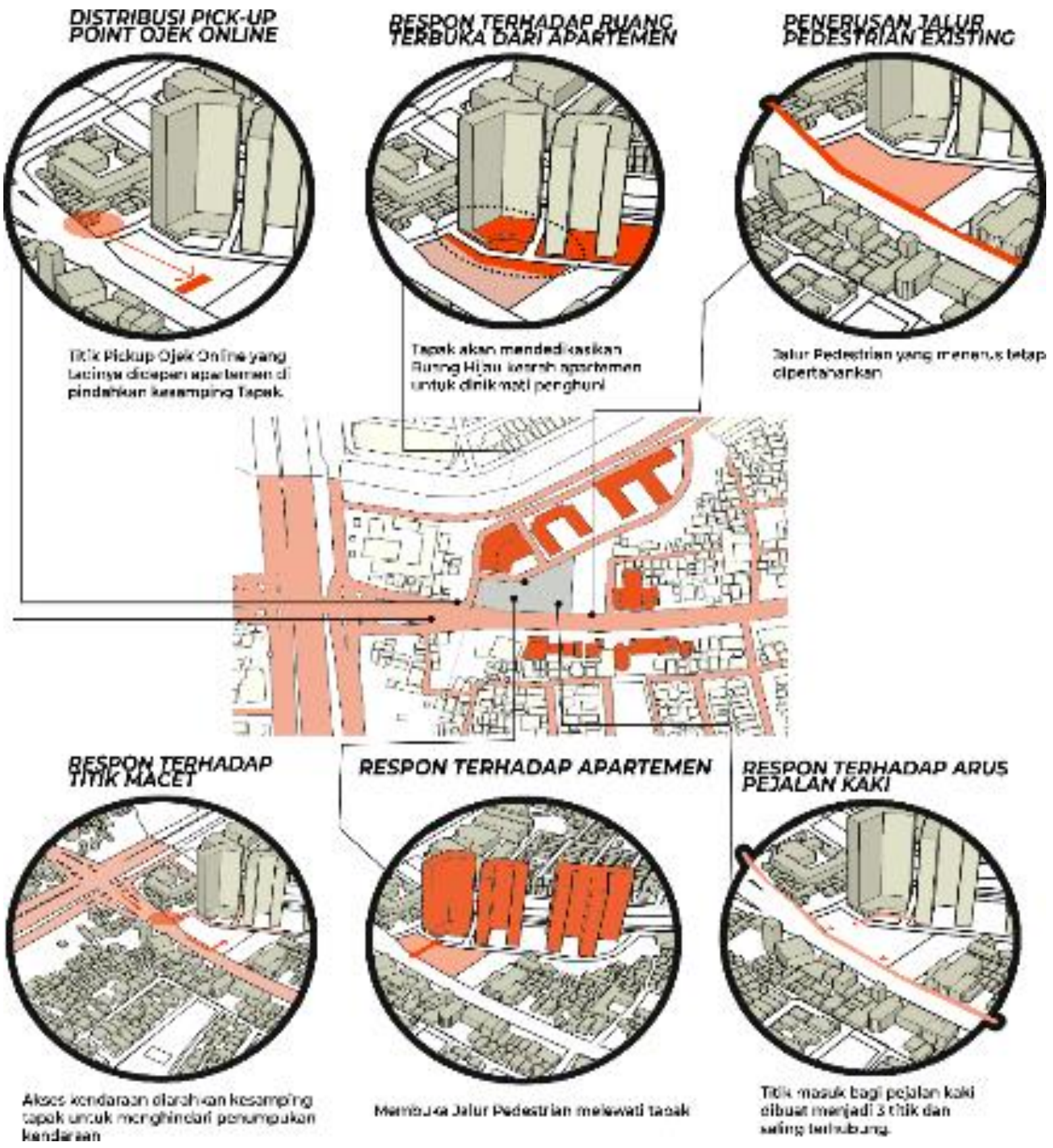

Gambar 4. Analisis Lokasi Sumber: Penulis, 2019

Analisis lokasi dilakukan agar bangunan yang dirancang dapat merespon keadaan sekitarnya sehingga program yang dirancang dapat berfungsi dengan maksimal. 


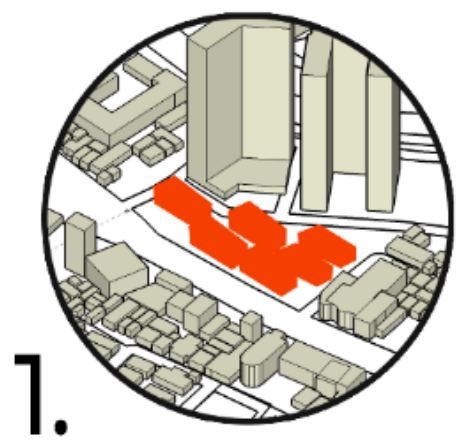

Kondisi tapak berupa Ruko dan rumah yang tidak sesuai dengan Zona peruntukan, Sehingga tapak dipilih untuk digunakan sesuai dengan peruntukannya yaitu zona pelayanan sosial

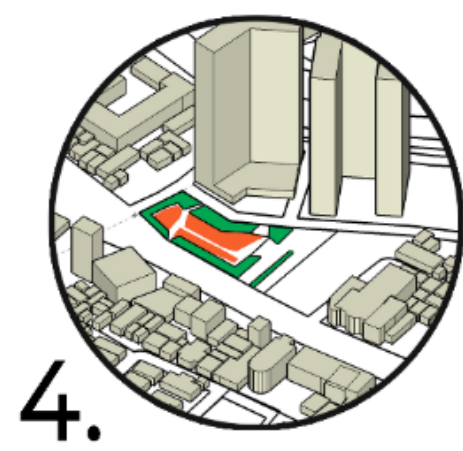

Penyesuaian antara area hijau, area yang akan dibangun dengan jalur sirkulasi dalam bangunan

\section{MASSING PROCESS}

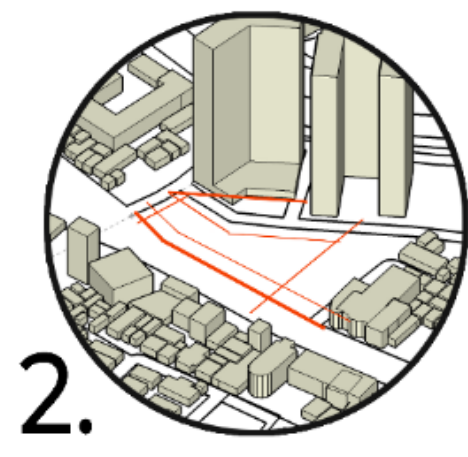

Tapak dikosong kan dan kondisi tapak dikelilingi oleh jalan. Perancangan dimulai dengan menentukan axis dari kawasan yang akan digunakan sebagai patokan dalam proses perancangan.

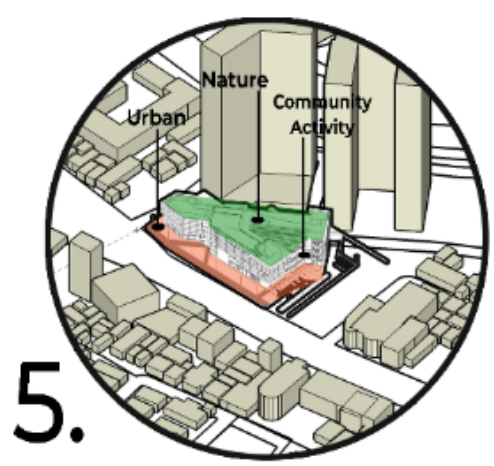

Bangunan kemudian di bagi programny dengan konsep Urban to Nature dimana lantai terbawah merupakan area komersil dan lantai teratas di dedikasikan untuk Taman dan kegiatan komunitas diantaranya.

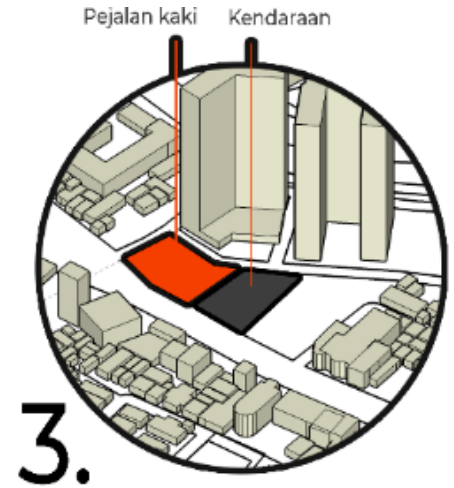

Pembagian tapak menjadi 2 zona, Bagian yang dekat dengan Apartemen didedikasikan untuk pejalan kaki, sedangkan bagian lainnya menjadi zona servis dan kendaraan.

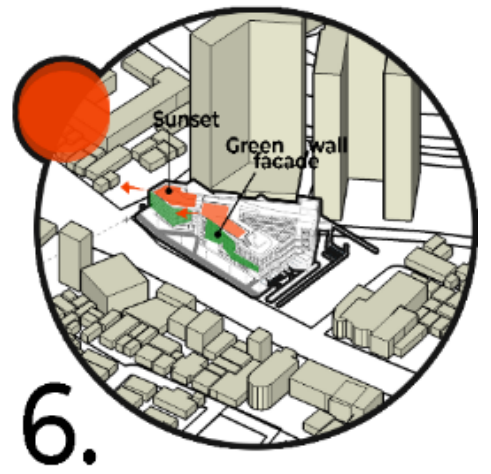

Untuk merespon Matahari Barat, Fasad bangunan yang menghadap barat di tutupi dengan second skin berupa tanaman rambat.

Lantai teratas yang merupakan taman juga menyediakan tempat untuk mengamati sunset indah yang menghadap ke CBD Puri

Gambar 5. Skema Desain Massa Bangunan Sumber: Penulis, 2019

\section{Konsep Bangunan}

Konsep bangunan yang dirancang difokuskan pada menciptakan suasana yang santai dan nyaman bagi pengunjungnya. Bangunan yang dirancang terdiri dari 4 lantai dimana lantai paling dasar didedikasikan untuk kegiatan komersil, lantai ke 2 untuk kegiatan komunitas, lantai 3 untuk area makan dan lantai ke 4 untuk area ruang hijau terbuka. Dengan demikian tersusun alur dimana Dari lantai paling bawah merupakan suasana urban dan publik dan semakin naik keatas suasana yang didapatkan semakin personal, dan dekat dengan alam. 


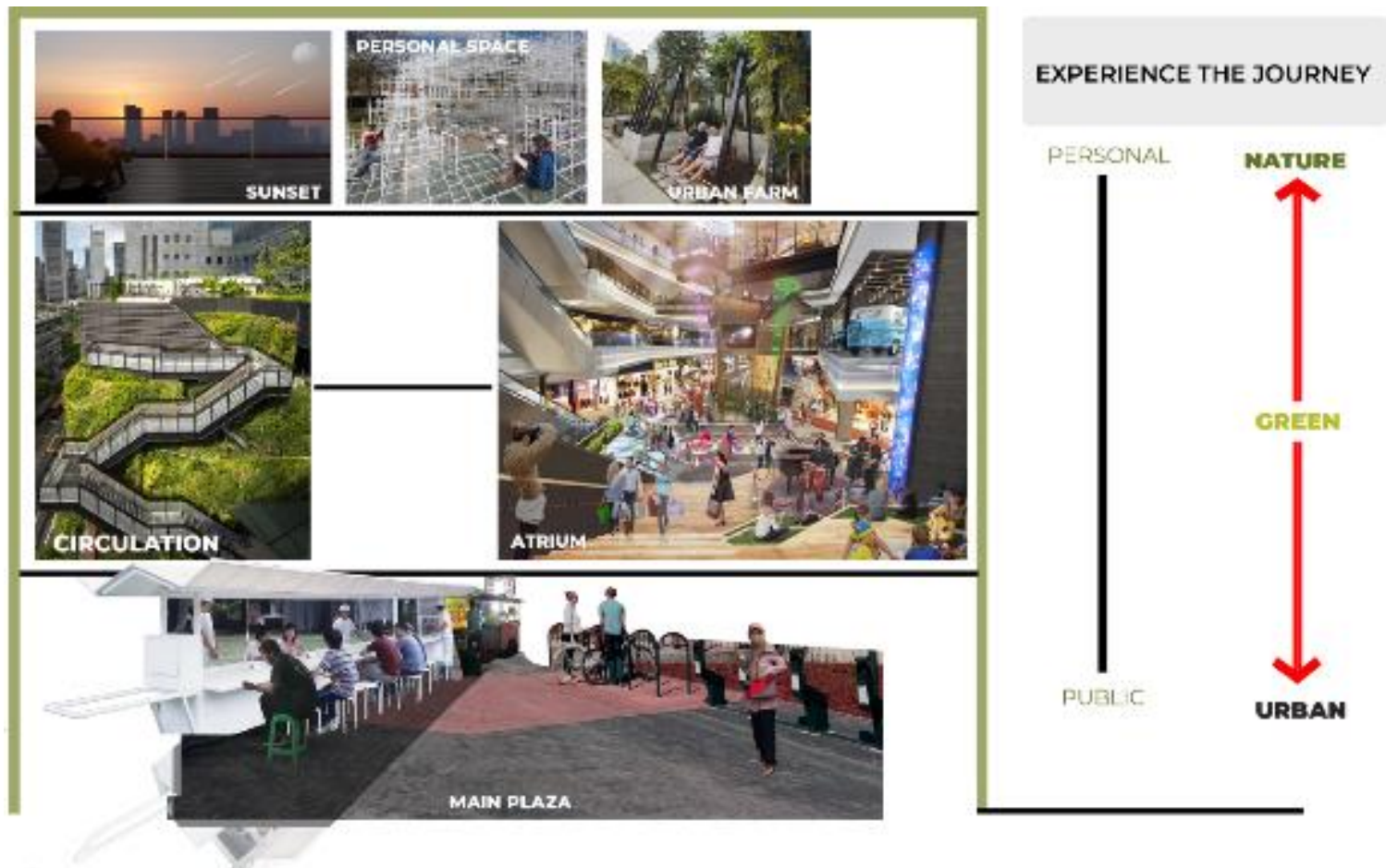

DESIGN VISION

Gambar 6. Konsep dan Visi desain bangunan.

Sumber: Penulis, 2019

\section{KESIMPULAN DAN SARAN}

Pada akhir penelitian ini, dapat ditarik beberapa kesimpulan, antara lain; dalam mewadahi kegiatan masyarakat di kota, arsitektur dapat menghadirkan program yang mampu menjadi katalis. Dimana program yang dihasilkan dapat memicu interaksi sosial antar masyarakat yang dimulai dari penduduk sekitar yaitu penghuni apartemen puri park view. Dengan terjadinya interaksi maka masyarakat dapat memulai koneksi dalam berbagai bidang mulai dari sosial, ekonomi, budaya, edukasi, hingga hiburan. Masyarakat dapat merasakan dampak positif dari bersosialisasi terutama bagi masyarakat masa kini yang sibuk dengan kesehariannya dapat menemukan tempat dan waktu untuk bersosialisasi. Pada akhirnya dengan adanya interaksi positif, dalam skala jangka panjang program dapat membantu memberikan dampak bagi perkembangan daerah yang dilayani.

\section{REFERENSI}

Akbar, Y. \&. (2012). Determinant of Factor That Influence Consumer in Choosing Normal FullService Restaurant. Malaysia: Seri Iskandar.

Hall, E. (1959). The Silent Language. New York City: Double day \& Company.

Johan W., A. H. (2018). Faktor Yang Mempengaruhi Keputusan Konsumen Dalam Memilih Restoran "All You Can Eat" di Surabaya. 14.

Myers-Briggs. (2019, August 27). Myersbriggs.org. Retrieved from https://www.myersbriggs.org/my-mbti-personality-type/mbti-basics/extraversion-orintroversion.htm?bhcp $=1$

Oldenburg, R. (1989). The Great Good Place. Cambridge Centre, USA: Paragon House. 